\title{
ON THE PHENOMENON OF "CRYPTOCURRENCY" AND THE VALIDITY OF THIS TERM IN THE MODERN LEGAL LEXICON
}

\author{
Peter M. Filippov \\ Volgograd Academy of the Ministry of Internal Affairs of the Russian Federation, \\ Volgograd, Russian Federation \\ Vitalii A. Sadkov \\ Volgograd Academy of the Ministry of Internal Affairs of the Russian Federation, \\ Volgograd, Russian Federation
}

Introduction: the paper deals with the phenomenon denoted by the term "cryptocurrency" from the perspective of modern civil circulation, its relationship with other statutory concepts which characterize the digital economy. It is necessary to introduce the term "electronic fiducion" into the legal lexicon to denote the phenomenon that is known as "cryptocurrency" at the everyday level. The authors' definition of the category "electronic fiducion" is proposed. The purpose of the study is to conduct a comprehensive legal analysis of the phenomenon referred to at a simple level as "cryptocurrency" from the perspective of the object of civil relations. Methods: the methodological framework for the study is a set of methods of scientific knowledge, among which the main ones are the methods of analysis, synthesis, generalization and comparative law. Results: the authors' well-founded position is based on the legislation and the opinions of the competent scientists on the issues of determining the legal essence of the category, which is now referred to as "cryptocurrency" from the perspective of civil law. Conclusions: as a result of the study the authors proposed to introduce in the legal lexicon, instead of the term "cryptocurrency", the term "electronic fiducion" which denotes the universal contractual payment (settlement) means with the decentralized record of the transactions based on free will and good faith, free from the external administration used by the contractors on the telecommunication network "Internet".

Key words: ctyptocurrency, digital financial assets, digital rights, e-fiducion, bitcoin.

Citation. Filippov P.M., Sadkov V.A. On the Phenomenon of "Cryptocurrency" and the Validity of this Term in the Modern Legal Lexicon. Legal Concept, 2020, vol. 19, no. 1, pp. 16-23. (in Russian). DOI: https://doi.org/10.15688/lc.jvolsu.2020.1.2

\section{О ФЕНОМЕНЕ «КРИПТОВАЛЮТА» И ДОПУСТИМОСТИ ЭТОГО ТЕРМИНА В СОВРЕМЕННОМ ЮРИДИЧЕСКОМ ЛЕКСИКОНЕ}

\section{Петр Мартынович Филиппов}

Волгоградская академия Министерства внутренних дел Российской Федерации, г. Волгоград, Российская Федерация 


\section{Виталий Андреевич Садков}

Волгоградская академия Министерства внутренних дел Российской Федерации, г. Волгоград, Российская Федерация

Введение: в статье рассматривается феномен, обозначаемый термином «криптовалюта», с позиций элемента современного гражданского оборота, его соотношение с другими правовыми конструкциями, характерными для цифровой экономики. Обусловливается необходимость введения в юридический лексикон термина «электронный фидуцион» для обозначения явления, которое на бытовом уровне именуется «криптовалютой». Предлагается авторское определение категории «электронный фидуцион». Целью исследования является проведение комплексного правового анализа явления «криптовалюта» с позиций объекта гражданских правоотношений. Методы: методологическую основу данного исследования составляет совокупность методов научного познания, среди которых основное место занимают анализ, синтез, обобщение и сравнительное правоведение. Результаты: обоснованная в работе авторская позиция опирается на законодательство и мнения компетентных ученых по вопросам определения правовой сущности категории, которая сегодня именуется как «криптовалюта», с позиций цивилистики. Выводы: в результате исследования авторами предложено ввести в юридический лексикон вместо термина «криптовалюта» термин «электронный фидуцион», которым обозначается универсальное договорное платежное (расчетное) средство с децентрализованным учетом совершаемых операций, основанное на свободе воли и добросовестности, свободное от внешнего администрирования, используемое контрагентами в информационно-телекоммуникационной сети Интернет.

Ключевые слова: криптовалюта, цифровые финансовые активы, цифровые права, электронный фидуцион, биткойн.

Цитирование. Филиппов П. М., Садков В. А. О феномене «криптовалюта» и допустимости этого термина в современном юридическом лексиконе // Legal Concept = Правовая парадигма. - 2020. - T. 19, № 1. C. 16-23. -DOI: https://doi.org/10.15688/lc.jvolsu.2020.1.2

\section{Введение}

Программой «Цифровая экономика Российской Федерации» установлено, что обеспечение эффективного развития России в условиях интенсификации применения цифровых технологий в экономике требует создания соответствующих институтов и инфраструктуры, обеспечивающих должное взаимодействие всех акторов (субъектов, участников) цифровой экономики [8]. Думается, что в качестве одного из таких институтов следует рассматривать феномен, созданный на основе информационной технологии блокчейн, на бытовом уровне некорректно именуемой как «криптовалюта».

\section{Соотношение категории «криптовалюта» с другими категориями современного гражданского права}

Изначально блокчейн-технология разрабатывалась для одноранговой децентрализованной системы электронных расчетных средств, получивших обозначение «биткойн». Система биткойн позволяет держателям электронных кошельков, взаимодействующим в сети Интернет, совершать не только макро-, но и микроплатежи, минуя официальные финансовые институты и финансовых посредников [6, с. 1]. Биткойн-транзакции подтверждаются всеми участниками этой системы, они не могут произвольно отменяться или корректироваться, а информация о проведенных операциях отражается в виде цепочки последовательных блоков, защищенных от попыток взлома криптографическим ключом, и доступна каждому [17, с. 104]. С «легкой» руки экономиста А. Гринберга для обозначения этого нового явления, получившего достаточно широкое распространение, стал употребляться термин «криптовалюта». Нередко это явление легкомысленно обозначается и другим термином - «цифровые деньги» [3], что по представлениям лиц, не обладающих специальными познаниями в сфере гражданского и финансового права, вполне допустимо.

Оперативность, защищенность и псевдоанонимность платежей в системе биткойн, их независимость от внешнего, прежде всего государственного, администрирования стимулировали создание иных криптовалютных систем, которых в современном интернет-простран- 
стве насчитывается более двух с половиной тысяч. Повсеместное распространение цифровых телекоммуникационных технологий позволяет получить доступ к той или иной криптовалютной системе в любом месте, для чего достаточно лишь обладать устройством, имеющим подключение к сети Интернет, и соответствующим программным обеспечением.

Тем не менее единого мнения о месте и сущности категории, обозначаемой как «криптовалюта», в современном мире нет. Сегодня демонстрируются различные позиции относительно допустимости использования феномена «криптовалюта» - от предложений по полному законодательному запрету ее использования до рассмотрения криптовалюты в качестве панацеи от всех болезней современной экономики.

В. Усоский утверждает, что криптовалюта - это цифровое имущество (товар), произведенное майнерами и выраженное в форме математического кода, который соответствует объему энергии, затраченной на выработку новой цепочки блоков в системе блокчейн. По мнению этого ученого, криптовалюта не является обязательством и существует в виртуальном криптографическом пространстве вне экономических механизмов спроса на кредитные деньги со стороны производителей, она является «техногенным мифом» и при этом относится к категории «средство бартерного обмена» $[12$, с. 36,44$]$. При всем уважении к вышеуказанному автору мы отмечаем противоречивость его позиции и неспособность объяснить широкую востребованность криптовалюты среди ее пользователей.

В.К. Шайдуллина, раскрывая суть криптовалюты, понимает под ней совокупность определенных единиц (криптомонет), создаваемых посредством использования математического кода с элементами криптографии с учетом транзакций в цифровой среде и при отсутствии единого эмиссионного центра $[16$, c. 106]. Однако, давая такое определение криптовалюты, данный автор не обозначает ее место в экономическом обороте. Сведение криптовалюты только к математическому коду, соответствующему объему потраченной на ее выработку энергии (так называемой оцифрованной энергии), некорректно, так как в этих определениях не в полной мере отра- жена значимость криптовалюты как объекта общественных отношений. Думается, что при определении сущности феномена «криптовалюта» необходимо прежде всего ориентироваться на криптовалюту как на объект гражданских прав, то есть на то благо, по поводу которого складываются отношения между субъектами гражданского оборота.

Анализ вышеприведенных точек зрения показывает, что большинство исследователей сосредоточивают свое внимание на таких свойствах феномена «криптовалюта», как криптозащищеность, волатильность, децентрализованность, допустимость использования в качестве договорного расчетного средства, но не вдаются в проблематику правомерности описания исследуемого феномена посредством использования терминов «валюта» и «деньги», а также его возможной характеристики как эквивалента стоимости материальных ценностей в гражданском обороте. Однако этот вопрос является принципиальным.

Российское законодательство дает однозначный ответ на вопрос о том, что считать деньгами. Согласно ст. 75 Конституции РФ [5], «рубль является денежной единицей в Российской Федерации», а право денежной эмиссии предоставлено Центральному банку РФ. Эмиссия других денег в РФ не допускается. Статья 140 Гражданского кодекса РФ [1] (далее - ГК РФ) развивает положения Конституции РФ о том, что рубль является законным платежным средством, обязательным к приему по нарицательной стоимости на всей территории РФ, а платежи на территории РФ осуществляются путем наличных и безналичных расчетов.

Федеральным законом РФ от 27 июня 2011 г.№ 161-Ф3 «О национальной платежной системе» [14] установлена законность существования национальной электронной платежной системы и электронных средств платежа. По данному закону электронные деньги приравниваются к безналичной форме расчета, их использование возможно только после идентификации плательщика и получателя платежа в установленном законодательством порядке. Фактически электронные деньги могут выступать легальным эквивалентом ценности вещей в гражданском обороте. То есть «криптовалюта» не относится к катего- 
рии «деньги» в том смысле, в котором это указано в действующем российском законодательстве. Деньги в РФ - это только банкноты и монеты Банка России (то есть наличные деньги), безналичные денежные средства в рублях и электронные денежные средства, учитываемые в рублях.

Что касается допустимости применения для описания одноранговой децентрализованной системы электронных расчетных средств термина «валюта», то с позиции действующего российского законодательства это достаточно проблематично.

Согласно ст. 1 Федерального закона РФ от 10 декабря 2003 г. № 173-Ф3 «О валютном регулировании и валютном контроле» [13], под валютой Российской Федерации понимаются: 1) денежные знаки в виде банкнот и монеты Банка России, находящиеся в обращении в качестве законного средства наличного платежа на территории Российской Федерации, а также изымаемые либо изъятые из обращения, но подлежащие обмену указанные денежные знаки; 2) средства на банковских счетах и в банковских вкладах. К иностранной валюте российский законодатель относит: 1) денежные знаки в виде банкнот, казначейских билетов, монеты, находящиеся в обращении и являющиеся законным средством наличного платежа на территории соответствующего иностранного государства (группы иностранных государств), а также изымаемые либо изъятые из обращения, но подлежащие обмену указанные денежные знаки; 2) средства на банковских счетах и в банковских вкладах в денежных единицах иностранных государств и международных денежных или расчетных единицах.

Следует учитывать, что в некоторых странах национальным законодательством так называемые виртуальные деньги легализованы на государственном уровне (например, в Республике Беларусь [4]), но о наделении их статусом национальной валюты говорить нельзя.

В настоящее время можно утверждать, что прямого законодательного запрета на использование объектов, описываемых термином «криптовалюта», в гражданском обороте Российской Федерации нет. Руководствуясь закрепленным в ст. 1 ГК РФ принципом сво- боды установления гражданских прав и обязанностей на основании договора и определении любых не противоречащих законодательству условий договора, российский законодатель отреагировал на появление сделок с использованием новых явлений, свойственных современной цифровой среде [1]. 25 января 2018 г. на обсуждение общественности был представлен законопроект № 419059-7, который первоначально именовался «О цифровых финансовых активах». В ст. 2 данного законопроекта, подготовленного к первому чтению, под цифровым финансовым активом предлагалось понимать имущество в электронной форме, созданное с использованием криптографических средств и не являющееся законным средством платежа на территории Российской Федерации, а криптовалюту рассматривать как одну из разновидностей цифровых финансовых активов, создаваемую и учитываемую в распределенном реестре цифровых транзакций участниками этого реестра в соответствии с правилами ведения реестра цифровых транзакций [9]. Считаем правильным то, что в законопроекте указывается статус цифрового финансового актива как имущества.

Анализируя приведенные определения, следует отметить, что они не только не помогают понять сущность данных явлений, но и, напротив, порождают новые вопросы, на которые в законопроекте ответов нет. Во первых, формулировка «имущество в электронной форме» (применительно к категории «цифровые финансовые активы») не состыковывается с общепринятым в юриспруденции употреблением термина «форма», который применяется к способам фиксации волеизъявления сторон сделки (например, ст. 158 ГК РФ именуется как «Форма сделок», ст. 493 ГК РФ именуется как «Форма договора розничной купли-продажи» и пр.) [2]. В действующем российском гражданском законодательстве и цивилистической доктрине категория «форма» к видам имущества не применяется. Вовторых, говоря о правилах ведения реестра цифровых транзакций (применительно к категории «криптовалюта»), нет ясности, кто и каким образом эти правила устанавливает, какие санкции предусмотрены за нарушение этих правил. 
Отмечая противоречивость и слабую проработанность текста законопроекта № 419059-7, подготовленного к первому чтению, А.О. Иншакова и А.И. Гончаров предлагают вместо термина «криптовалюта» употреблять термин «расчетная цифровая криптозапись» и считают необходимым серьезным образом переработать данный документ, а наименование проектируемого федерального закона сформулировать следующим образом: «Об операциях с шифрами в информационнотелекоммуникационной сети “Интернет”" По справедливому мнению вышеназванных ученых, некорректные формулировки законопроекта позволяют сделать вывод о том, что целью создания криптовалюты может выступать шифроигра «на настоящие деньги», а в качестве сути формирования цифровых финансовых активов может рассматриваться создание финансовой пирамиды, объединяющей анонимных участников, идентификация и защита прав которых невозможна априори [7, c. 333,344$]$.

По итогам рассмотрения законопроект № 419059-7 ко второму чтению получил наименование «О цифровых финансовых активах и о внесении изменений в отдельные законодательные акты Российской Федерации (о цифровых финансовых активах)», а его положения существенно изменились. В соответствии с текстом п. 2 ст. 1 новой редакции законопроекта под цифровыми финансовыми активами предлагается понимать цифровые права, включающие обязательственные и иные права, в том числе денежные требования, возможность осуществления прав по эмиссионным ценным бумагам, право требовать передачи эмиссионных ценных бумаг, которые закреплены в решении о выпуске цифровых финансовых активов в порядке, установленном Федеральным законом «О цифровых финансовых активах и о внесении изменений в отдельные законодательные акты Российской Федерации (о цифровых финансовых активах)», выпуск, учет и обращение которых возможны только путем внесения (изменения) записей в информационной системе на основе распределенного реестра [10].

Из содержания вышеуказанной редакции законопроекта можно сделать вывод о том, что под цифровыми финансовыми активами предлагается понимать только определенный сегмент цифровых прав, которые выпускаются, учитываются и обращаются посредством совершения определенных записей в информационной системе на основании специального распределенного реестра. Следует отметить, что в тексте анализируемого законопроекта, подготовленного для второго чтения в Государственной думе РФ, такое понятие, как «криптовалюта», вообще отсутствует, но предлагается ввести в оборот такую категорию, как «цифровые операционные знаки», под которыми разработчики законопроекта понимают совокупность электронных данных (цифрового кода или обозначения), полученных по правилам информационных систем, которые не относятся к категории «цифровые финансовые активы». Примечательно, что выпуск и использование цифровых операционных знаков планируется осуществлять под контролем Банка России [10].

Мы можем обоснованно предположить, что под термином «цифровые операционные знаки» авторы текста законопроекта № 419059-7, подготовленного ко второму чтению в Государственной думе РФ, понимают категорию, которая на бытовом уровне обозначается термином «криптовалюта». Несомненно, что такая интерпретация сущности криптовалюты вступает в серьезные противоречия с ее первоначальной идеей - как финансового инструмента, свободного от внешнего администрирования.

Неудивительно, что на такую редакцию анализируемого законопроекта поступило большое количество негативных отзывов. Это обусловило перенос его рассмотрения на апрель 2020 г., тогда как 18 марта 2019 г. был принят Федеральный закон РФ № 34-Ф3 «О внесении изменений в части первую, вторую и статью 1124 части третьей Гражданского кодекса Российской Федерации» [15], в котором в перечень объектов гражданских прав был включен такой специфический феномен, как «цифровые права». Нормы ст. 141.1 ГК РФ определяют, что под цифровыми правами следует понимать обязательственные и иные права, содержание и условия осуществления которых определяются в соответствии с правилами информационной системы, отвечающей установленным законом признакам, а осу- 
ществление, распоряжение и обременение цифрового права или ограничение распоряжения цифровыми правами возможны только в информационной системе без обращения к третьему лицу [1].

Думается, что значимость цифровых прав, принадлежащих тому или иному субъекту, заключается в их признании другими участниками гражданского (хозяйственного) оборота, взаимодействующими в электронной среде, а внешняя форма выражения такой оценки чаще всего охватывается категорией «обменный курс». Данный курс показывает ценность того или иного имущественного права в перерасчете на рубли или единицы зарубежной валюты.

Мы полагаем, что сущность категории «цифровые права» нельзя сводить только к цифровым технологиям, которые, по мнению А.В. Степанченко, по своей сути являются способом фиксации имущественных притязаний участников гражданского оборота, обладающих правовой защитой [11, с. 519]. Цифровые права - это более широкая категория, которая является базовой для другой категории - цифровые финансовые активы.

При сопоставлении категорий «цифровые права», «цифровые финансовые активы» и того, что на бытовом уровне именуется «криптовалютой», следует соотносить их как общее с частным: цифровые финансовые активы являются одним из сегментов цифровых прав, а криптовалюта - разновидностью цифровых финансовых активов. Мы обращаем внимание на тот факт, что даже несмотря на отсутствие четкого законодательного регулирования оборота криптовалюты в Российской Федерации, объем этого оборота ежегодно растет, а сама криптовалюта все активнее используется населением для удовлетворения различных потребностей.

\section{Выводы}

На наш взгляд, современное общество является свидетелем трансформации понимания денег как средства платежа, вызванной слиянием реального и виртуального миров. При этом думается, что использование термина «криптовалюта», который прижился в сознании людей на бытовом уровне, в профессио- нальной среде некорректно. На наш взгляд, по аналогии соотношения терминов «интеллектуальная собственность» и «право на результаты интеллектуальной деятельности» вместо термина «криптовалюта» следует ввести в юридический лексикон термин «электронный фидуцион», который более точно отражает суть описываемого явления. Дефиниция категории «электронный фидуцион» может быть сформулирована следующим образом: электронный фидуцион - это универсальное договорное платежное (расчетное) средство с децентрализованным учетом совершаемых операций, основанное на свободе воли и добросовестности, свободное от внешнего администрирования, используемое контрагентами в информационно-телекоммуникационной сети «Интернет».

Данное определение следует закрепить в законодательстве, регламентирующем гражданский оборот цифровых финансовых активов.

\section{СПИСОК ЛИТЕРАТУРЫ}

1. Гражданский кодекс Российской Федерации (часть первая) от 30 ноября 1994 г. № 51-Ф3 : (с послед. изм.).- Доступ из справ.-правовой системы «КонсультантПлюс».

2. Гражданский Кодекс Российской Федерации (часть вторая) от 26 января 1996 г. № 14-ФЗ (с послед. изм.). - Доступ из справ.-правовой системы «КонсультантПлюс».

3. Гринберг, Э. Криптовалюта / Э. Гринберг. Электрон. текстовые дан. - Режим доступа: https:// www.forbes.com/forbes/2011/0509/technologypsilocybin-bitcoins-gavin-andresen-cryptocurrency.html\#6dac5a51353e (дата обращения: 23.12.2019). - Загл. с экрана.

4. Декрет Президента Республики Беларусь от 21 декабря 2017 г. № 8 «О развитии цифровой экономики». - Электрон. текстовые дан. - Режим доступа: http://president.gov.by/ru/official_documents_ru/ view/dekret-8-ot-21-dekabrja-2017-g-17716/ (дата обращения: 23.12.2019). - Загл. с экрана.

5. Конституция Российской Федерации от 25 дек. 1993 г. // Российская газета. - 2009. - 21 янв.

6. Накамото, С. Биткойн: система цифровой пиринговой наличности. - Электрон. текстовые дан. - Режим доступа: https://bitcoin.org/files/ bitcoin-paper/bitcoin_ru.pdf (дата обращения: 23.12.2019). - Загл. с экрана.

7. Объекты гражданских прав : учебник для бакалавриата, специалитета и магистратуры / под 
ред. А. И. Гончарова, А. О. Иншаковой. -2-е изд. М. : Юрайт ; Волгоград : Изд-во ВолГУ, 2019. - 567 с.

8. Программа «Цифровая экономика Российской Федерации» : Распоряжение Правительства РФ от 28 июля 2017 г. № 1632-p. - Доступ из справ.правовой системы «КонсультантПлюс».

9. Проект Федерального закона № 419059-7 «О цифровых финансовых активах» (текст к первому чтению). - Электрон. текстовые дан. - Режим доступа: http://sozd.duma.gov.ru/download/ 16A3CC43-AF85-49EC-9821-2D0C8F1E7E8A (дата обращения: 20.12.2019). - Загл. с экрана.

10. Проект Федерального закона № 419059-7 «О цифровых финансовых активах и о внесении изменений в отдельные законодательные акты Российской Федерации (о цифровых финансовых активах)» (текст ко второму чтению). - Электрон. текстовые дан. - Режим доступа: http://static. consultant.ru/obj/file/doc/pr_fz210319_2.rtf(дата обращения: 20.12.2019). - Загл. с экрана.

11. Степанченко, А. В. К вопросу о правовой сущности криптовалюты / А. В. Степанченко // Пермский юридический альманах. - 2019. - № 1. С. 510-519.

12. Усоский, В. Криптовалюта как техногенный миф / В. Усоский // Банкаўскі веснік, КРАСАВІК. 2019. - С. 35-48. - Электрон. текстовые дан. - Режим доступа: https://www.nbrb.by/bv/articles/ 10620.pdf (дата обращения: 20.12.2019). - Загл с экрана.

13. Федеральный закон от 10 декабря 2003 г. № 173-Ф3 «О валютном регулировании и валютном контроле». - Доступ из справ.-правовой системы «КонсультантПлюс».

14. Федеральный закон от 27 июня 2011 г. № 161-Ф3 «О национальной платежной системе». - Доступ из справ.-правовой системы «КонсультантПлюс».

15. Федеральный закон от 18 марта 2019 г. № 34-Ф3 «О внесении изменений в части первую, вторую и статью 1124 части третьей Гражданского кодекса Российской Федерации». - Доступ из справ.-правовой системы «КонсультантПлюс».

16. Шайдуллина, В. К. Криптовалюта: прогноз развития в условиях современного финансового рынка / В. К. Шайдуллина // Экономические науки. 2018. - № 12. - С. 106-111. - Электрон. текстовые дан. - Режим доступа: https://ecsn.ru/files/pdf/ 201812/201812_106.pdf(дата обращения: 20.12.2019). Загл. с экрана.

17. Шнейдерова, Д. И. Противодействие использованию цифровой валюты в процессе совершения хищений / Д. И. Шнейдерова // Сетевое издание «Академическая мысль». -2019. - № 1 (6). - С. 104-107.Электрон. текстовые дан. - Режим доступа: https:// cyberleninka.ru/article/n/protivodeystvie- ispolzovaniyu-tsifrovoy-valyuty-v-protsessesoversheniya-hischeniy/viewer (дата обращения: 20.12.2019). - Загл. с экрана.

\section{REFERENCES}

1. Grazhdanskiy kodeks Rossiyskoy Federatsii (chast pervaya) ot 30 noyabrya 1994 g. № 51-FZ: (s posled. izm.) [Civil Code of Russian Federation (Part One) dated November 30, 1994 no. 51-FZ (with changes and additions)]. Access from Reference Legal System "ConsultantPlus".

2. Grazhdanskiy kodeks Rossiyskoy Federatsii (chast vtoraya) ot 26 yanvarya 1996 g. № 14-FZ: (s posled. izm.) [Civil Code of Russian Federation (Part Two) dated January 26, 1996 no. 14-FZ (with changes and additions)]. Access from Reference Legal System "ConsultantPlus".

3. Grinberg E. Kriptovalyuta [Cryptocurrency]. URL: https://www.forbes.com/forbes/2011/0509/ technology-psilocybin-bitcoins-gavin-andresencrypto-currency.html\#6dac5a51353e (accessed 23 December 2019).

4. Dekret Prezidenta Respubliki Belarus ot 21 dekabrya $2017 \mathrm{~g}$. № 8 «O razvitii tsifrovoy ekonomiki» [Decree no. 8 of the President of the Republic of Belarus of 21 December 2017 "On the Development of the Digital Economy"]. URL: http:// president.gov.by/ru/official_documents_ru/view/ dekret-8-ot-21-dekabrja-2017-g-17716/ (accessed 23 December 2019).

5. Konstitutsiya Rossiyskoy Federatsii of 25 Dec. 1993 [The Constitution of the Russian Federation]. Rossiyskaya gazeta [Russian Newspaper], 2009, 21 Jan.

6. Nakamoto S. Bitkoyn: sistema tsifrovoy piringovoy nalichnosti [Bitcoyn: Digital Peer Cash System]. URL: https://bitcoin.org/files/bitcoin-paper/ bitcoin_ru.pdf(accessed 23 December 2019).

7. Goncharov A.I., Inshakova A.O., eds. Obyekty grazhdanskikh prav: uchebnik dlya bakalavriata, spetsialiteta i magistratury [Objects of Civil Rights: Textbook for Bachelor's Degree, Specialization and Master's Degreedited]. Moskow, Yurayt Publ.; Volgograd, Izd-vo VolGU, 2019. 567 p.

8. Programma «Tsifrovaya ekonomika Rossiyskoy Federatsii»: Rasporyazhenie Pravitelstva RF ot 28 iyulya 2017 g. № 1632-r [Program "Digital Economy of the Russian Federation": Order of the Government of the Russian Federation of July 28, 2017 no. 1632-p]. Access from Reference Legal System "ConsultantPlus".

9. Proekt Federalnogo zakona № 419059-7 "O tsifrovykh finansovykh aktivakh» (tekst $k$ pervomu chteniyu) [Draft Federal Law no. 419059-7 "On Digital Financial Assets" (text for the first 
reading)]. URL: http://sozd.duma.gov.ru/download/ 16A3CC43-AF 85-49EC-9821-2D0C8F1E7E8A (accessed 20 December 2019).

10. Proekt Federalnogo zakona № 419059-7 "O tsifrovykh finansovykh aktivakh $i$ o vnesenii izmeneniy $v$ otdelnye zakonodatelnye akty Rossiyskoy Federatsii (o tsifrovykh finansovykh aktivakh)» (tekst ko vtoromu chteniyu) [Draft Federal Law no. 419059-7 “On Digital Financial Assets and on Amendments to Certain Legislative Acts of the Russian Federation (on Digital Financial Assets)" (text for the second reading)]. URL: http://static. consultant.ru/ obj/file/doc/pr_fz210319_2.rtf(accessed 20 December 2019).

11. Stepanchenko A.V. K voprosu o pravovoy sushchnosti kriptovalyuty [To the Question of the Legal Essence of Crypto]. Permskiy yuridicheskiy almanakh [Perm Legal Almanac], 2019, no. 1, pp. 510-519.

12. Usoskij V. Kriptovalyuta kak tekhnogennyy mif [Cryptocurrency as a Man-Made Myth]. Bankayski vesnik, KRASAVIK [Bank Messenger], 2019, pp. 35-48. URL: https://www.nbrb.by/bv/articles/ 10620.pdf(accessed 20 December 2019).

13. Federalnyy zakon ot 10 dekabrya $2003 \mathrm{~g}$. № $173-\mathrm{FZ}$ «O valyutnom regulirovanii i valyutnom kontrole» [Federal Law No. 173-FZ of 10 December 2003 "On Foreign Exchange Regulation and Control"]. Access from Reference Legal System "ConsultantPlus”.
14. Federalnyyzakon ot 27 iyunya 2011 g. № 161-FZ «O natsionalnoy platezhnoy sisteme» [Federal Law no. 161-FZ of 27 June 2011 on the National Payment System]. Access from Reference Legal System "ConsultantPlus".

15. Federalnyy zakon ot 18 marta 2019 g. № $34-F Z$ «O vnesenii izmeneniy v chasti pervuyu, vtoruyu $\mathrm{i}$ statyu 1124 chasti tretey Grazhdanskogo kodeksa Rossiyskoy Federatsii» [Federal Law no. 34-FZ of 18 March 2019 "On Amendments to Parts One, Two and 1124 of Part Three of the Civil Code of the Russian Federation"]. Access from Reference Legal System "ConsultantPlus".

16. Shajdullina V.K. Kriptovalyuta: prognoz razvitiya $\mathrm{V}$ usloviyakh sovremennogo finansovogo rynka [Cryptocurrency: Forecast of Development in the Conditions of the Modern Financial Market]. Ekonomicheskie nauki [Economic Sciences], 2018, no. 12, pp. 106-111. URL: https://ecsn.ru/files/pdf/ 201812/201812_106.pdf(accessed 20 December 2019).

17. Shnejderova D.I. Protivodeystvie ispolzovaniyu tsifrovoy valyuty $\mathrm{v}$ protsesse soversheniya hishcheniy [Countering the Use of Digital Currency in Theft]. Setevoe izdanie «Akademicheskaya mysl», 2019, no. 1 (6), pp. 104-107. URL: https://cyberleninka.ru/article/n/ protivodeystvie-ispolzovaniyu-tsifrovoy-valyuty-vprotsesse-soversheniya-hischeniy/viewer (accessed 20 December 2019).

\section{Information About the Authors}

Peter M. Filippov, Doctor of Sciences (Jurisprudence), Professor, Honored Lawyer of the Russian Federation, Honorary Worker of Higher Professional Education of the Russian Federation, Department of Civil Law Disciplines, Volgograd Academy of the Ministry of Internal Affairs of the Russian Federation, Istoricheskaya St., 130, 400089 Volgograd, Russian Federation, civillaw34@yandex.ru, https://orcid.org/0000-0001-5439-8382

Vitalii A. Sadkov, Captain of Police, Junior Scientific Assistant, Postgraduate Department, Volgograd Academy of the Ministry of Internal Affairs of the Russian Federation, Istoricheskaya St., 130, 400089 Volgograd, Russian Federation, wrendek@mail.ru, https://orcid.org/0000-0002-5171-7023

\section{Информация об авторах}

Петр Мартынович Филиппов, доктор юридических наук, профессор, заслуженный юрист РФ, почетный работник высшего профессионального образования РФ, профессор кафедры гражданско-правовых дисциплин, Волгоградская академия Министерства внутренних дел Российской Федерации, ул. Историческая, 130, 400089 г. Волгоград, Российская Федерация, civillaw34@yandex.ru, https://orcid.org/0000-0001-5439-8382

Виталий Андреевич Садков, капитан полиции, адъюнкт адъюнктуры, Волгоградская академия Министерства внутренних дел Российской Федерации, ул. Историческая, 130, 400089 г. Волгоград, Российская Федерация, wrendek@mail.ru, https://orcid.org/0000-0002-5171-7023 